\title{
O PROTAGONISMO DE PESSOAS COM DEFICIÊNCIA INTELECTUAL NO PROCESSO DE ENSINO- APRENDIZAGEM DA CAPOEIRA
}

\author{
André da Silva Mello \\ Universidade Federal do Espírito Santo, Vitória, Espírito Santo, Brasil \\ Wagner dos Santos \\ Universidade Federal do Espírito Santo, Vitória, Espírito Santo, Brasil \\ Laís Albuquerque Rodrigues \\ Universidade Federal do Espírito Santo, Vitória, Espírito Santo, Brasil \\ Renata de Souza Santos \\ Universidade Federal do Espírito Santo, Vitória, Espírito Santo, Brasil
}

\begin{abstract}
Resumo
Este trabalho analisa o protagonismo de deficientes intelectuais no processo de ensinoaprendizagem da capoeira em um projeto de extensão universitária. Adotamos os "Estudos com o Cotidiano" como pressuposto teórico-metodológico e, no processo de análise, utilizamos dados produzidos por diferentes fontes, como observação participante, entrevistas semiestruturadas e registro iconográfico. A análise dos dados demonstra que o projeto focalizou as suas ações nas figuras do aprender valorizadas pelos deficientes intelec tuais, que se evidenciaram, sobretudo, nos aspectos rítmicos e musicais da capoeira e na solidariedade. A falta de formação específica de professores/monitores para atuar na perspectiva pedagógica almejada foi o principal desafio para que o projeto alcançasse as suas metas.
\end{abstract}

Palavras-chave: Deficientes Intelectuais. Capoeira. Ensino-Aprendizagem. Protagonismo.

\section{Introdução}

O processo de inclusão social de pessoas com deficiência física e/ou intelectual tem avançado nas últimas décadas no Brasil. No plano legal, ${ }^{1}$ há um conjunto de normas que buscam garantir a dignidade e a cidadania dessas pessoas. No

\footnotetext{
${ }^{1}$ A inclusão social orientou a elaboração de políticas e leis na criação de programas e serviços voltados ao atendimento das necessidades especiais de deficientes nos últimos 50 anos.
} 
contexto educacional, ${ }^{2}$ as escolas adaptam as suas práticas pedagógicas e as suas estruturas para proporcionar o acesso do deficiente à educação formal e, no campo do lazer, ${ }^{3}$ políticas públicas são articuladas para atender às demandas específicas desses sujeitos. Essas ações denotam a preocupação do Poder Público e da sociedade civil em superar relações permeadas pelo preconceito e pela exclusão, que historicamente foram estabelecidas com os diferentes. Para Machado (2009, p. 34): “A inclusão, assim, representa um movimento de 'des-adjetivar' o substantivo diferença, que tem sido impregnado de conotações pejorativas aliadas à questão da deficiência".

Apesar dos avanços, ainda há um longo percurso para que o processo de inclusão se efetive em nossa sociedade. Os desafios estão circunscritos em diferentes dimensões e vão desde questões estruturais mais abrangentes, como o investimento na formação de professores aptos a contribuir para o desenvolvimento dos sujeitos com deficiências no contexto da Educação Básica, até a superação de representações presentes no nosso cotidiano, que concebem esses sujeitos como incapazes e improdutivos.

No caso específico da deficiência intelectual, foco de interesse deste estudo, Oliveira (2009, p. 136) afirma que as representações que circulam no imaginário social estão associadas

[...] à incapacidade, à eterna infância, à dependência e provocam sentimentos de superproteção ou de desprezo. A pessoa com deficiência intelectual é discriminada, estigmatizada, colocada numa posição social desfavorável, inferior. Entretanto, esse quadro é encoberto por palavras de carinho e assistencialismo.

Nessa perspectiva, os sujeitos com deficiências intelectuais são concebidos pela sua negatividade, ou seja, pelas suas carências e faltas, por aquilo que não conseguem fazer. Suas possibilidades e potencialidades são suprimidas por estigmas que os rotulam como dependentes, subjugando-os à "misericórdia alheia". Os "outros" é que têm a prerrogativa de lhes imputar o que é bom, pois eles são considerados incapazes de pensar sobre si mesmos, e "[...] dirige-se à pessoa com deficiência intelectual uma série de preconceitos que enaltecem seus déficits e apagam ou menosprezam suas características efetivas e criativas" (OLIVEIRA, 2009, p.137).

As suas vozes são silenciadas por pessoas que, sob o pretexto de ajudá-los, muitas vezes não conhecem e nem reconhecem as suas necessidades, expectativas e interesses. Nos diferentes contextos de inserção social dos sujeitos com deficiên-

\footnotetext{
2 Diretrizes Nacionais para a Educação Especial na Educação Básica (2001).

3 Lei $n^{\circ} 82 / 2009$, do município de Montes Claros/MG, que permite o acesso gratuito de deficientes às atividades de lazer.
} 
cias intelectuais, são estabelecidas relações assimétricas de poder, que ignoram o seu protagonismo ${ }^{4}$ e os fazem agir de maneira automatizada, como "marionetes" nas mãos de pessoas bem intencionadas que reforçam e reproduzem práticas e representações preconceituosas.

Apesar do peso das representações que estão cristalizadas, “[...] com um novo olhar, percebe-se que as pessoas com deficiência intelectual também podem agir, reagir, interagir e criar novas leituras e soluções" (OLIVEIRA, 2009, p. 150). Entretanto, para que isso aconteça, é preciso "escovar a contra pelo" (BENJAMIN, 1993), ou seja, é necessário concebê-las de outra maneira, tirando o foco de sua deficiência e direcionando-o para as suas possibilidades, atribuindo-lhes "voz", para que sejam autores das práticas e discursos sobre si mesmos.

É nesse contexto que se insere este estudo. Analisamos as possibilidades e os desafios para efetivar práticas pedagógicas que considerem o protagonismo das pessoas com deficiências intelectuais no processo de ensino-aprendizagem da capoeira. Para tanto, inserimo-nos no cotidiano do projeto de extensão "Arranjos didático-metodológicos para o ensino da capoeira para jovens e adultos com deficiência intelectual", desenvolvido no Laboratório de Educação Física Adaptada (Laefa) do Centro de Educação Física e Desportos da Universidade Federal do Espírito Santo.

Nesse sentido, são objetivos deste estudo: a) Analisar, a partir das relações que os jovens e adultos com deficiências intelectuais estabeleceram com a capoeira, o protagonismo desses sujeitos no processo de ensino-aprendizagem dessa manifestação cultural; b) Discutir os desafios encontrados no cotidiano do projeto para se efetivar uma prática pedagógica centrada no protagonismo dos participantes.

\section{Percurso teórico-metodológico}

Esta pesquisa tem como delineamento teórico-metodológico os Estudos Com o Cotidiano (CERTEAU, 1994; ALVES, 2008; FERRAÇO, 2008), em que a prática pedagógica assume uma centralidade nos processos interpretativos empreendidos. Só é possível entender o cotidiano e as suas lógicas de operação, por meio de um mergulho na realidade das ações pedagógicas e nunca exercitando o olhar distante e neutro, propugnado pela ciência na modernidade.

Nesse sentido, inserimo-nos, durante um ano, no cotidiano das aulas de capoeira destinadas a jovens e adultos com deficiência intelectual, desenvolvidas no Laefa. As intervenções ocorreram uma vez por semana, sempre às quintas-feiras, no horário das 14 às 16 horas. A turma era composta por 29 alunos, sendo $10 \mathrm{mu}$ lheres e 19 homens, na faixa etária entre 12 e 38 anos. No grupo trabalhado

${ }^{4}$ Compreendemos como protagonismo, no contexto do projeto pesquisado, o processo de coautoria e de codecisão dos deficientes intelectuais nas ações pedagógicas empreendidas, que estão associadas aos seus interesses, necessidades e possibilidades.

Pensar a Prática, Goiânia, v. 17, n. 1, p. 01-294, jan./mar. 2014 
havia diversas patologias, com predomínio da Síndrome de Down, do autismo e da paralisia cerebral.

Ao defender a centralidade das práticas, os Estudos com o Cotidiano buscam perceber o que não está explicitamente em evidência. Almeja compreender, para além das aparências, as lógicas operatórias dos sujeitos envolvidos no cotidiano, decifrar o que ainda não foi dito e, de certa forma, efetuar uma "arqueologia das práticas". Desse modo, os fragmentos, os detalhes revelados no contexto das práticas pedagógicas se constituem como importantes aspectos de análise dos conhecimentos produzidos pelos praticantes no cotidiano, pois, como afirma Ferraço (2008, p. 46): “[...] é preciso o desenvolvimento de metodologias de pesquisa que possam contribuir para que se tornem perceptíveis os sentidos dos fragmentos desprezíveis e irrelevantes, porque eles são mediadores de articulações complexas".

Para Alves (2008), a pesquisa com o cotidiano envolve quatro atitudes fundamentais. A primeira é captar o "sentimento do mundo", o que pressupõe sentir o cheiro, os gostos, ouvir os sons produzidos nos diferentes contextos educacionais, extrapolando, dessa forma, a apropriação do real apenas pelo olhar neutro e distante. Nessa perspectiva, procuramos nos envolver diretamente com as práticas pedagógicas desenvolvidas, compartilhando com os sujeitos as suas emoções, tensões, frustrações e narrativas. Durante as aulas, interagimos diretamente com os participantes, por meio de conversas, toques e expressões.

A segunda atitude é "virar de ponta cabeça", o que significa ver a realidade sobre outra ótica. Dessa forma, o nosso olhar se dirigiu às potencialidades, ou seja, para aquilo que os jovens e adultos participantes do projeto de extensão são capazes de fazer, e não para as suas deficiências e impossibilidades. A terceira atitude implica valorizar as narrativas produzidas pelos sujeitos, pois os Estudos com o Cotidiano consideram a linguagem como elemento constituinte do ser humano, que constrói o mundo e a si mesmo por meio das suas atividades comunicativas. Alves (apud FERRAÇO, 2008, p. 26) argumenta sobre a validade das narrativas como fonte:

Entre as questões teórico-metodológicas, as narrativas, originadas das conversas, depoimentos ou escritos pessoais, formando um tipo especial de texto, vêm permitindo desenvolver tanto as metodologias próprias da história oral e da história de vida, como uma história de biografias de pessoas comuns, acumulando dados de caráter antropológico, etnográfico e sociológico o que faz ressaltar a posição transdisciplinar da educação, bem como a importância dos dados assim obtidos para esse tipo de pesquisa.

Embora concordemos com Oliveira (2009) que a linguagem verbal é condição básica para que a pessoa com deficiência intelectual expresse os seus dese- 
jos e interesses, ressaltamos que, no grupo pesquisado, existem participantes que não dispõem desse sistema simbólico ou o apresentam de forma bastante limitada. Portanto, é preciso que estejamos atentos a outros tipos de linguagens, como a expressiva e a gestual, pois elas são pistas indiciárias (GINZBURG, 1987) que denotam o grau de envolvimento e o interesse pela atividade desenvolvida. Apesar de parcela significativa do grupo analisado não possuir uma linguagem verbal articulada, valorizamos os seus breves excertos de fala, enunciados na dinâmica das aulas e nas conversas com os pares e professores.

Por fim, a quarta atitude é a de "beber em todas as fontes", pois os dados produzidos nas diferentes fontes formam redes complexas de análise, superando, assim, a interpretação fragmentada e unilateral da realidade. Utilizamos dados produzidos por meio da observação participante, que foram sistematizados em diário de campo, com narrativas dos sujeitos, ${ }^{5}$ captadas por meio de entrevistas semiestruturadas e em situações espontâneas de aula e imagens iconográficas. No processo de interpretação, os sentidos foram construídos na articulação de dados oriundos de diferentes fontes, considerando o contexto sociointeracional em que foram produzidos.

\section{A relação com o saber: pistas para ações pedagógicas centradas no protago- nismo dos sujeitos com deficiência intelectual}

Neste tópico, utilizaremos a primeira pessoa do plural no processo de apresentação e análise dos dados, pois, nos Estudos com o Cotidiano, os pesquisadores procuram "fazer com" em vez de "falar de". Nessa perspectiva, a nossa inserção no cotidiano das práticas pedagógicas do projeto não ocorreu de maneira distanciada, mas participando ativamente das ações empreendidas.

$\mathrm{O}$ projeto se deparou com várias dificuldades em valorizar o protagonismo dos jovens e adultos no processo de ensino-aprendizagem da capoeira. A principal delas estava circunscrita na dimensão metodológica, em "como fazer". Como valorizar o protagonismo de pessoas que não falam ou falam muito pouco? Como identificar os seus interesses em relação à capoeira? Essas indagações demarcaram os desafios encontrados no que se refere à efetivação das práticas pedagógicas centradas no protagonismo dos sujeitos com deficiências intelectuais.

Inicialmente, insistimos na promoção do diálogo, pois desejávamos que os participantes do projeto se expressassem verbalmente, que falassem o que pensavam e o que sentiam em relação à capoeira, mas não obtivemos êxito com essa estratégia. Como descrevemos, os envolvidos no projeto apresentavam restrições na linguagem verbal. Desse modo, não conseguimos extrair das suas falas elementos que subsidiassem a nossa intervenção pedagógica, além de percebermos que a tentativa de "dar voz" aos participantes do projeto, na verdade, gerava uma situação

\footnotetext{
${ }^{5}$ Além dos jovens e adultos com deficiências intelectuais, consideramos, como sujeitos, a professora, os monitores e o coordenador do projeto.
}

Pensar a Prática, Goiânia, v. 17, n. 1, p. 01-294, jan./mar. 2014 
artificial, voltada para atender às nossas expectativas e não, de fato, aos interesses e necessidades deles.

Diante dessa constatação, alteramos a nossa estratégia de ação e passamos a observar o modo como os participantes do projeto "consumiam" as informações sobre a capoeira que lhes eram oferecidas. Ao considerarmos que os produtos culturais não são "consumidos passivamente", admitimos que os sujeitos ressignificam e dão uma conotação própria àquilo que lhes é ofertado (CERTEAU, 1994). Há uma estética da recepção, que confere marcas singulares e identitárias aos produtos culturais, e que precisa ser considerada nos processos de intervenção pedagógica para que as especificidades de grupos sociais distintos sejam atendidas.

No curso de um ano de atividades no projeto, percebemos que os sentidos e significados atribuídos à capoeira pelos alunos deficientes intelectuais tinham características próprias. Em várias situações, os participantes apresentavam formas originais e autônomas de se relacionar com a capoeira. Diante de tal constatação, focalizamos o conceito de "relação com o saber", proposto por Charlot (2000), para identificar as figuras do aprender valorizadas pelos sujeitos na sua interação com a capoeira no contexto do projeto pesquisado.

Todo saber é uma relação com o objeto do saber. De acordo com Charlot (2000, p. 61), “[...] não se poderia, para definir a relação com o saber, partir do sujeito da razão, pois para entender o sujeito do saber, é preciso entender sua relação com o saber". Esse autor diferencia informação de saber. A informação é exterior ao indivíduo e pode ser estocada, está sob "a primazia da objetividade". Já o saber é o resultado de uma experiência individual e coletiva relacionada com uma atividade, é uma informação apropriada de maneira intersubjetiva.

Bondía (2001) afirma que a informação é contrária à experiência. Informação é o que acontece, enquanto a experiência é o que nos acontece. A experiência é uma relação com algo que se experimenta, que se prova. A relação com o saber pressupõe a experiência com o conhecimento, que não pode se separar do indivíduo, de sua situação existencial e singular. Se a elaboração do sentido que os sujeitos estabelecem na relação com o saber está ligada à experiência, trata-se, então, de um saber finito, associado à existência de um indivíduo ou de uma comunidade humana particular.

Charlot (2000) ressalta que só existe o saber em ato, pois o mesmo é uma relação que resulta da interação que o sujeito mantém com o mundo. Como afirma o autor, “[...] não há saber senão para um sujeito, não há saber senão organizado de acordo com as situações internas, não há saber senão produzido em uma confrontação interpessoal" (CHARLOT, 2000, p. 61). Saber é diferente de aprender. Aprender é exercer uma atividade em situação: em um local específico, em certo período histórico, sob determinadas condições.

Orientados por esses pressupostos, compreendemos as formas específicas com que os participantes do projeto se relacionavam com os saberes provenientes da capoeira. Inicialmente, o foco das nossas ações centrou-se na aprendizagem 
dos fundamentos dessa manifestação cultural, pois tínhamos a expectativa de que os participantes se apropriassem dos movimentos básicos, como a ginga, as esquivas, alguns golpes e movimentos coreográficos simples. A aprendizagem desses fundamentos foi mediada pela musicalidade, que ora ocorria pela música mecânica (CD), ora ocorria com o toque dos instrumentos (berimbau, atabaque e pandeiro).

No decorrer das aulas, percebemos que os interesses dos alunos estavam mais direcionados aos aspectos rítmicos e musicais do que aos fundamentos da capoeira. Esse interesse se revelou, fundamentalmente, na "linguagem corporal" apresentada pelos alunos. A alegria, o nível de excitação e de vibração dos participantes com as atividades mediadas pela musicalidade se explicitavam de maneira latente nas suas expressões corporais. Os relatos abaixo, extraídos do diário de campo, fornecem indícios desse interesse:

A aluna Mirela ${ }^{6}$ e o aluno Tales foram tocar o atabaque. Antes de a música começar, a aluna Mirela começou a bater no atabaque o toque do início da música com muita facilidade. Aproveitamos esse momento e começamos a ensaiar. Os alunos estavam bem integrados, batendo palma e cantando. Thiago, como sempre, se mostra muito contente por estar tocando o atabaque (Diário de campo, 12-5-2011).

No momento de relembrarmos algumas músicas que aprendemos na capoeira nesse período, o aluno Rômulo puxou as palmas e toda a turma respondeu. Inicialmente, cantamos a música É o A, é o B, é o A, é o B, é o C. Os alunos Jefinho e Fabiano tocaram os instrumentos enquanto a turma cantava, e o aluno Rômulo se levantou para acompanhar os colegas nos instrumentos, tocando com toda a empolgação (Diário de campo, 229-2011).

Devido à motivação dos participantes, as intervenções pedagógicas do projeto passaram a focalizar os aspectos rítmicos e musicais da capoeira. Essa motivação se manifestou, sobretudo, nas atitudes desses participantes, denotando a importância do corpo e do movimento como uma forma de narrativa que evidencia os seus interesses. Para Pérez-Samaniego (2011, p. 22):

[...] las narrativas no solo son construcciones lingüísticas o textuales; nuestro cuerpo también cuenta historias y las narrativas también están corporeizadas. [...] La conexión entre la corporeidad y las narrativas se basa en la idea de que llegamos a cono-

\footnotetext{
${ }^{6}$ Os nomes apresentados são fictícios, a fim de preservar as identidades e o anonimato dos participantes da pesquisa.
} 
cer nuestro cuerpo y el de los otros a través de historias que contamos y nos cuentan sobre muy distintos aspectos de la corporeidad. $^{7}$

Ao enfatizarmos os aspectos rítmicos e musicais no trato com a capoeira, percebemos que a linguagem verbal dos participantes, antes pouco presente, começou a se manifestar com mais frequência. A verbalização ocorreu, principalmente, nos momentos mediados pelas músicas da capoeira, oportunizando o agir autônomo e criativo de alguns indivíduos, como se evidencia no seguinte diálogo extraído do diário de campo:

[...] o aluno Fabiano sugeriu que cantássemos a música 'Peixe vai, peixe vem'. A professora Laís perguntou se ele queria cantar 'Chuva vai, chuva vem', pois essa é a forma da canção original. Fabiano disse que não, que era 'Peixe vai, peixe vem'. A monitora Renata falou para a professora Laís que o aluno Fabiano havia ressignificado a música e ele complementou dizendo que poderia terminar com 'Peixe miúdo não morde ninguém'. Então cantamos todos juntos a 'nova' música (Diário de campo, 2010-2011).

Apesar de os participantes não apresentarem uma linguagem verbal articulada, os fragmentos das suas falas evidenciam que eles não consomem passivamente os produtos culturais que lhes são oferecidos. Eles ressignificam e produzem cultura, exigindo do "outro" um olhar atento para essas diferentes formas de produção. Como afirmam Poupart et al. (2008, p. 51), é preciso tornar visível aquilo que "[...] se tornou invisível, por excesso de visibilidade", ou seja, é necessário desnaturalizar a representação da pessoa com deficiência como sinônimo de incapacidade, e enxergar as atitudes de valorização e reconhecimento da inventividade de suas práticas que são ignoradas pelo rótulo do preconceito.

Nesse sentido, buscamos potencializar esses fragmentos de fala, pois, conforme Oliveira (2009, p. 143), a interlocução é muito importante, mas não basta apenas ter acesso à linguagem humana para que ela exista, ela também deve ser autorizada pelo outro para seu uso, pois: “[...] quando não se reconhece o papel da pessoa com deficiência intelectual como interlocutor, cria-se uma cena de suposto respeito, pois a pessoa fala, contudo verdadeiramente não se considera efetivamente o valor de sua mensagem".

\footnotetext{
${ }^{7}$ Tradução: “[...] as narrativas não são apenas construções linguísticas ou textuais; nosso corpo também conta histórias e as narrativas também são incorporadas. A conexão entre corporeidade e a narrativa baseia-se na ideia de que chegamos a conhecer nosso próprio corpo e dos outros por meio de histórias que contamos e que nos contam sobre aspectos muito diferentes de corporeidade".
} 
$\mathrm{Na}$ intenção de promover o protagonismo dos participantes, solicitamos que eles elaborassem um desenho sobre a capoeira e sugerissem um nome para o grupo. Propusemos que o desenho que eles escolhessem seria estampado na camisa do batizado ${ }^{8}$ assim como o nome sugerido para o grupo. O registro iconográfico abaixo, extraído da camisa do batizado, demonstra o desenho e os nomes escolhidos:

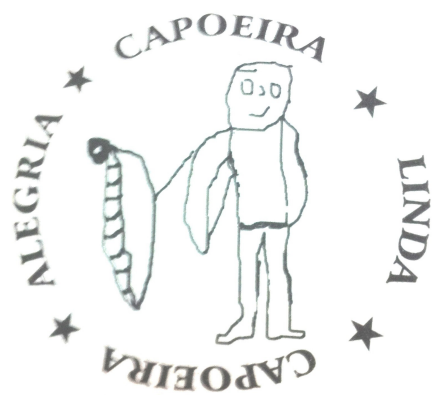

No desenho, vê-se uma pessoa sorrindo, segurando o berimbau. Essa imagem expressa, mais uma vez, o interesse dos participantes pela dimensão rítmica e musical da capoeira. Quanto ao nome, duas sugestões empataram na preferência dos participantes: linda e alegria. Esses dois nomes foram escolhidos para representar o grupo.

Essas escolhas denotam as relações de prazer e de alegria que os jovens e adultos participantes do projeto de extensão estabeleceram com a capoeira, relações que foram mediadas pela afetividade e pela solidariedade. Charlot (2000) denomina essa figura do aprender de "saber relacional", pois quem aprende é o sujeito afetivo e relacional, constituído por sentimentos e emoções. É fruto das relações e situações em que se encontra um sujeito encarnado, temporal e provido de afetividade. São formas relacionais de saber, como a solidariedade, a amizade, a perseverança, que são aprendidas em ato, em situações concretas de experimentações e não apenas de verbalizações.

Os participantes do projeto são extremamente afetivos. Com frequência, eles abraçavam e beijavam a professora e os monitores do projeto na chegada e na saída das atividades. Traziam "lembranças" pra eles, como desenhos, frutas ou objetos, e verbalizavam os seus sentimentos. A partir dessa constatação, as ações pedagógicas do projeto passaram a valorizar essas relações, que foram mediadas no trato com a capoeira, sobretudo, pelas canções. A promoção da amizade e da solidariedade foi potencializada por meio das músicas de capoeira, como na seguinte canção:

\footnotetext{
${ }^{8} \mathrm{Na}$ tradição da capoeira, batizado é um evento em que o novo praticante é apresentado à comunidade capoeirista e recebe a primeira graduação (cordel). Esse ritual foi instituído por Manoel dos Reis Machado, o Mestre Bimba.
} 
Camarada o que é meu?

É meu irmão (coro)

Irmão do coração camarada

É meu irmão (coro)

Me dá um aperto de mão

É meu irmão (coro)

Pois lhe trago no coração

Além de cantar com entusiasmo, os participantes do projeto (re)produziam, com os gestos, o enunciado das canções, transformando as aulas em uma grande festa, que se estendia para os pais ou responsáveis que acompanhavam as atividades, como se evidencia na narrativa da professora do projeto:

Terminamos a roda com a música Adeus! Adeus! Boa viagem! Eu vou me embora! Boa viagem!, com alguns alunos tocando instrumentos, outros dançando, despedindo um a um. A aula já havia acabado, mas o fato de estarem todos juntos tocando e cantando, como numa grande festa, fazia-os continuar na sala. Os pais também se aproximaram e participaram desse momento.

A interação dos alunos com os pais propiciou o desenvolvimento da solidariedade e cooperação. O fragmento da fala de uma mãe, destacado a seguir, revela essa construção promovida pelas intervenções pedagógicas: "[...] trato os filhos dos outros como se fossem os meus filhos"A solidariedade, na acepção de Rorty (1994), ajuda-nos a compreender como os laços afetivos e de socialização são constituídos a partir da noção de pertencimento. A solidariedade, para ele, não é um valor universal, um traço inerente à personalidade humana: constrói-se e não se acha em estado natural. As contingências de tempo e do espaço de um dado contexto influenciam os indivíduos a diferentes maneiras de comportamento, sendo impossível encontrar um único contexto no qual vidas humanas possam ser explicadas e entendidas. A solidariedade, portanto, se manifesta no contexto em que ambientamos a nossa existência. Exprimimos a nossa solidariedade para aqueles que consideramos "um de nós". O "alargamento do círculo de nós" ocorreu, no grupo da capoeira, pelas práticas solidárias, como nos lanches coletivos, na confecção conjunta dos materiais para o batizado e na busca de recursos financeiros e materiais para a realização do evento.

Apesar dos êxitos relatados, a valorização do protagonismo dos alunos com deficiências intelectuais no processo de ensino-aprendizagem da capoeira não ocorreu de maneira harmônica. Além das questões metodológicas aqui descritas, a formação dos professores e monitores do projeto para atuar nessa perspectiva pedagógica foi um dos principais obstáculos para que o projeto alcançasse as suas metas. Nas reuniões de planejamento, a professora e os monitores expressavam 
suas angústias e inseguranças na condução das aulas, e um dos professores abandonou o projeto, alegando que não conseguia trabalhar na perspectiva almejada. Quando indagado sobre os desafios para desenvolver o protagonismo dos alunos no processo de ensino-aprendizagem da capoeira, o coordenador do projeto respondeu:

O maior desafio está em nós mesmos, não estamos preparados para trabalhar dessa forma. Na nossa formação, não tivemos nada disso. É muito difícil olhar para essas pessoas [deficientes intelectuais] sem o rótulo, sem preconceito. Mas é possível, estamos aprendendo isso, com muito estudo e dedicação é possível. É o dia a dia, é a rotina das aulas que aponta alguns caminhos interessantes $[\ldots]$.

Independentemente do êxito ou do fracasso do projeto no alcance das suas metas, compreendemos que o trabalho com pessoas com deficiência intelectual exige o desenvolvimento de novos conhecimentos, novas competências e de criatividade, em um esforço de experimentação. Para Martinez (2005, p. 112): "O essencial não é estar ou não preparado. Isso é sem dúvida importante, porém secundário em relação ao essencial: o compromisso com os mais desfavorecidos, o querer trabalhar para transformar essa situação [...]".

\section{Considerações finais}

A inclusão social de pessoas com deficiência intelectual requer mudanças de representações e de atitudes sobre elas. Concebê-las como sujeitos capazes, com potencialidades para expressar seus interesses e necessidades, é um importante passo para superar estigmas e preconceitos historicamente arraigados. No entanto, como constatamos neste estudo, não basta somente a intenção de considerar o protagonismo dos sujeitos, são necessários meios para operacionalizar essa intenção, especialmente nos processos educativos destinados a esse público.

As possibilidades são variadas. Dentre elas, destacamos a valorização das relações que os jovens e adultos com deficiências intelectuais estabelecem com o seu objeto do saber. Essas relações, advindas da experiência, podem se manifestar em diferentes figuras do aprender. No caso específico desta pesquisa, a dimensão rítmica/musical e a solidariedade foram as figuras do aprender mais valorizadas por eles. Essas, muitas vezes não estão explícitas, exigindo do outro um olhar atento para as pistas e indícios que revelem as suas expectativas, que nem sempre se manifestam pela linguagem verbal, mas, sobretudo, pelas narrativas corporais.

Ressaltamos o potencial do cotidiano na produção de conhecimentos para a prática pedagógica compromissada com o protagonismo dos deficientes intelectuais. Assim como Tardif (2002), compreendemos que o conhecimento não se 
adquire antes da prática, mas que ele se constitui no próprio trabalho pedagógico. Dessa forma, defendemos que os cursos de formação inicial em Educação Física focalizem, em seus currículos, desde cedo, as experiências de intervenção, materializando o que Santos (1989) denomina de "epistemologia da prática".

Por fim, destacamos a necessidade de novos estudos que invistam na indissociabilidade entre pesquisa, extensão e ensino. Eles podem gerar outras possibilidades para a formação inicial e continuada no ensino da capoeira com pessoas com deficiência intelectual, bem como para a produção de conhecimentos.

\title{
PEOPLE'S PROTAGONISM CONCERNING INTELLECTUAL DISABILITY IN THE TEACHING-LEARNING PROCESS OF CAPOEIRA
}

\begin{abstract}
The paper analyzes the protagonism of intellectual disabilities in the teaching-learning process of Capoeira in a university extension project. It uses the Everyday Life Studies as theoretical-methodological assumption and for the analysis process it uses data produced by different sources, such as, participant observation, semi-structures interviews and iconographic records. Data analysis indicates that the project focused their actions on learning figures valued by intellectual disabilities, which stood out, especially, in the rhythmic and musical aspects of Capoeira and in the solidarity as well. The lack of a specific formation of teachers/instructors when acting in the desired pedagogical perspective was the main challenge so that the Project could reach its goals.

Keywords: Intellectual disabilities. Capoeira. Teaching-learning. Protagonism.

\section{EL PROTAGONISMO PERSONAS CON DISCAPACIDAD INTELECTUAL EN EL PROCESO DE ENSEÑANZA-APRENDIZAJE DE LA CAPOEIRA}

\section{Resumen}

Analiza el papel de discapacidad intelectual de la capoeira de enseñanza-aprendizaje en un proyecto de extensión universitaria. Aprueba los estudios con la vida cotidiana como supuesto teórico y metodológico y, en el proceso de análisis utiliza los datos producidos por diferentes fuentes, tales como la observación participante, entrevistas semiestructuradas y registro iconográfico. Análisis de los datos muestra que el proyecto ha centrado sus acciones en las figuras de aprendizaje valoradas por personas con discapacidad intelectual, que mostraron principalmente en aspectos musicales y rítmicas de la capoeira y la solidaridad. La falta de formación específica de los profesores / líderes a actuar en la perspectiva deseada pedagógico fue el reto principal para que el proyecto alcance sus objetivos.

Palabras-clave: Discapacidad intelectual. Capoeira. La enseñanza y el aprendizaje. Protagonismo.

\section{Referências}

Pensar a Prática, Goiânia, v. 17, n. 1, p. 01-294, jan./mar. 2014 
ALVES, N. Sobre os movimentos das pesquisas nos/dos/com os cotidianos. In: ALVES, N.; OLIVEIRA, I. B. (Org.). Pesquisa nos/dos/com os cotidianos das escolas. 3. ed. Petrópolis: DP\&A, 2008.

BENJAMIN, W. O narrador: considerações sobre a obra de Nikolai Leskov. 5. ed. Rio de Janeiro: Editora Brasiliense, 1993.

BONDÍA, J. L. Notas sobre a experiência e o saber de experiência. Revista Brasileira de Educação, Campinas, n. 19, jan./ fev./ mar./ abr. 2001.

CERTEAU, M. A invenção do cotidiano. 10. ed. Petrópolis: Vozes, 1994.

CHARLOT, B. Da relação com o saber: elementos para uma teoria. Porto Alegre: Artes Médicas, 2000.

FERRAÇO, C. E. A pesquisa em educação no/do/com o cotidiano escolar. In: FERRAÇO, C. E.; PEREZ, C. L. V.; OLIVEIRA, I. B. Aprendizagens cotidianas com a pesquisa: novas reflexões em pesquisa nos/dos/com os cotidianos das escolas. Petrópolis: DP et Alii, 2008.

GINZBURG, C. O queijo e os vermes: o cotidiano e as idéias de um moleiro perseguido pela Inquisição. 3. ed. São Paulo: Companhia das Letras, 1987.

MACHADO, A. N. Rupturas necessárias para uma prática inclusiva. In: CONSELHO FEDERAL DE PSICOLOGIA. Educação inclusiva: experiências profissionais em psicologia. Brasília: CFP, 2009.

MARTÍNEZ, A. M. Inclusão escolar: desafios para o psicólogo. In: MARTÍNEZ, A. M. Psicologia escolar e compromisso social. Campinas: Alínea, 2005.

OLIVEIRA, V. M. O valor da enunciação da pessoa com deficiência intelectual. In: CONSELHO FEDERAL DE PSICOLOGIA. Educação inclusiva: experiências profissionais em psicologia. Brasília: CFP, 2009.

PÉREZ-SAMANIEGO, V. M. et al. La investigación narrativa en la educación física y el deporte: qué es y para qué sirve. Movimento, Porto Alegre, v.17, n.1, p.11-38, jan./mar. 2011.

POUPART, J. et al. A pesquisa qualitativa: enfoques epistemológicos e metodológicos. Petrópolis: Vozes, 2008. 
RORTY, R. Contingência, ironia e solidariedade. Lisboa: Editorial Presença, 1994.

SANTOS, B. S. Introdução a uma ciência pós-moderna. Rio de Janeiro: Gaal, 1989.

TARDIF, M. Saberes docentes e formação profissional. Petrópolis: Vozes, 2002.

Recebido em: 15/04/2013

Revisado em: 16/10/2013

Aprovado em: 11/11/2013

Endereço para correspondência:

andremellovix@gmail.com

André da Silva Mello

Universidade Federal do Espírito Santo

Centro de Educação Física e Desportos

Avenida Fernando Ferrari

Goiabeiras

29000-000 - Vitoria, ES - Brasil 